\title{
Application of industrial engineering in blazer making
}

\author{
Bishwajit Das *, Afsana Jerin Sumayea, Faiza Alam Kheya, Kazi-Noorjahan, Nusrat Zahan and Kaniz Tasmima \\ Sarwar
}

Department of Apparel Engineering, Textile Engineering College, Noakhali, Bangladesh.

Global Journal of Engineering and Technology Advances, 2021, 09(01), 011-035

Publication history: Received on 06 September 2021; revised on 08 October 2021; accepted on 10 October 2021

Article DOI: https://doi.org/10.30574/gjeta.2021.9.1.0136

\begin{abstract}
This paper is being developed in Blazer on industrial engineering. In the last few decades, the global economy, in particular in international commerce and manufacturing organizations, has evolved substantially. The technical framework of today is thus distinguished by productivity-oriented, which can be accomplished by industrial engineering. This paper presents the different principles \& approaches used in industrial engineering, such as time analysis, work studies, line balancing and the outcome of organizational disintegration tests in Blazer. This research has focused on several kinds of machinery to produce a Blazer. The traditional manufacturing industry has issues such as low efficiency, longer lead time, high rework \& re-work, poor line balance, low style shift flexibility, etc. The implementation of Industrial Engineering correctly resolved these issues. This study looks at how to develop Blazer's processes by using Industrial Engineering, wasting less resources, time, raw materials, human capital and electricity.
\end{abstract}

Keywords: Industrial Engineering; Raw materials; Resources; Manufacturing industry

\section{Introduction}

The garment manufacturing industry faces many global challenges due to various factors including competition, increased production costs, less productivity/efficiency and labor attribution. So, there is a need to focus and concentrate on identifying the real issues, taking corrective actions suited to the specific industrial center of the unit, empowering the technical and managerial staff by enhancing their knowledge and ability, analyzing orders efficiently and deciding whether actions are viable for the company. The world economy has changed in significant ways during the past several decades, especially in the areas of international trade and industrial organization. Two of the most important new features of the contemporary economy are the globalization of production and trade [1]. Therefore today's technological systems are characterized by orientation to productivity; this can be achieved through the apparel engineering. This paper introduces the various concepts and methods that have been used in Industrial Engineering as a part of Apparel Engineering in Garment industries. Generally, Industrial Engineering is defined an approach applied to all factors, including human factor involved in the production \& distribution of production and services. Now we can define Industrial Engineering (IE) as, Industrial engineering is concerned with the design, improvement and installation of integrated system of man, machine and equipment drawing upon specialized knowledge and skill in the technical, economics and human sciences, either with the principles or methods of engineering analysis and design to specify, predict and evaluate the results to be obtained from such system. The objectives of the industrial engineering and engineering management program are to produce [2]:

- $\quad$ Contribute to the success of companies through effective problem solving

- Design, develop, implement, and improve integrated systems that include people, materials, information, equipment, and environments

\footnotetext{
* Corresponding author: Bishwajit Das

Department of Apparel Engineering, Textile Engineering College, Noakhali, Bangladesh.

Copyright (C) 2021 Author(s) retain the copyright of this article. This article is published under the terms of the Creative Commons Attribution Liscense 4.0.
} 
- $\quad$ Effectively manage business operations and project management teams

- $\quad$ Continue to develop holistically, including the personal and professional skills necessary to adapt to our changing societal, technological, and global environments

- $\quad$ The industrial engineering and engineering management program are expected to meet the challenges for contemporary professional practice; be able to adapt and

Solve the increasingly complex problems faced by industry; embrace innovation through intellectual diversity and creative problem solving; and continue to develop holistically as a learner to become leaders of tomorrow responsibilities of IE [3]:

\subsection{Responsibility of Industrial Engineering}

- $\quad$ Planning layouts

- Monitoring Production flow system

- $\quad$ Decide the machines and attachments for all style

- $\quad$ Pay system

- $\quad$ Monitoring and improve the operator performance

- $\quad$ Operator training

- $\quad$ Production control system

- Quality control

- Others

\section{Objectives of the research}

- To know about industrial engineering

- To know about different parts of blazer

- $\quad$ To gather knowledge about operation breakdown of blazer

- $\quad$ To learn how to make blazer

- To know about different machine required for making a blazer

- To learn about measurement of blazer

- To gain knowledge about product development

- $\quad$ To produce various types of blazer

- $\quad$ To assist in forecasting by developing quality product

\section{Literature Review}

The sartorial term blazer originated with the red "blazers" of the Lady Margaret Boat Club (1825), the rowing club of St. John's College, Cambridge. The Lady Margaret club jackets were termed blazers because of the bright red cloth, and the term survived the original red coat. A writer to the London Daily News (22 August 1889) commented that "In your article of to-day ... you speak of 'a striped red and black blazer', 'the blazer', also of 'the pale toned' ones ... A blazer is the red flannel boating jacket worn by the Lady Margaret, St. John's College, Cambridge, Boat Club. When I was at Cambridge it meant that and nothing else. It seems from your article that a blazer now means a colored flannel jacket, whether for cricket, tennis, boating, or seaside wear. These early blazers were like later sports jackets, but this term has never referred to blazers, instead describing jackets derived from the later innovation of wearing odd jackets for landbased sports. Assertions that the name is derived from HMS Blazer are not borne out by contemporary sources, although it is reported that before the standardization of uniform in the Royal Navy, the crew of HMS Blazer wore "striped blue and white jackets",[2] apparently in response to the sailors of HMS Harlequin being turned out in harlequin suits.[3] As late as 1837 the gig's crew of HMS Blazer were dressed by their Captain in jackets of blue and white stripes and it is from this that the word blazer, meaning a striped jacket, has entered the language.[4]

The reefer jacket was of naval origin, and described the short double-breasted jacket worn by sailors in harsh weather, when they performed duties such as reefing the sails. It is descendants of this which are now commonly described by the term blazer. Originally with black horn buttons, these jackets evolved to the modern dark blazer, now single as well as double breasted, and with metallic buttons.

.[5] By the late 2000s the blazer had been adopted as a popular fashion trend amongst women, often having shorter lengths, rolled-up sleeves, various lapels and bright colors. Striped blazers became popular among British Mods in the early 1960s, and again during the Mod revival of the late 1970s - particularly in three-color thick/thin stripe combinations, with three-button single-breasted front, five- or six-inch side or canter vents, and cuffs with multiple 
buttons. Various photos from 1964 and 1965[6] show London mods in boating blazers. Photos of mod icons The Who from 1964 (as the High Numbers) variously show Pete Townshend, Keith Moon and John Entwisted wearing boating blazers. Another mod band, Small Faces, and other bands liked by modes - such as The Rolling Stones, The Beatles, The Kinks, Georgie Fame and the Blue Flames, The Animals, The Yardbirds, The Moody Blues and The Troggs - had band members wearing striped blazers/boating jackets, or later, brightly colored blazers with wide white or other light edging. These later blazers often had non-metal buttons, sometimes in the same color as the edging. The earlier style of striped blazers can be seen in the film Quadrophenia. The later, bright, style of blazer was affectionately adopted by Austin Powers as part of his Swinging-London look. [7]

\subsection{Best Blazers in black color for men \& women}

Here few type of blazers in black which can be worn differently according to situations as shown in Fig 1 .. Then don't forget to carry your black blazer with you. Going out with friends for a brunch or attending a wedding after work?

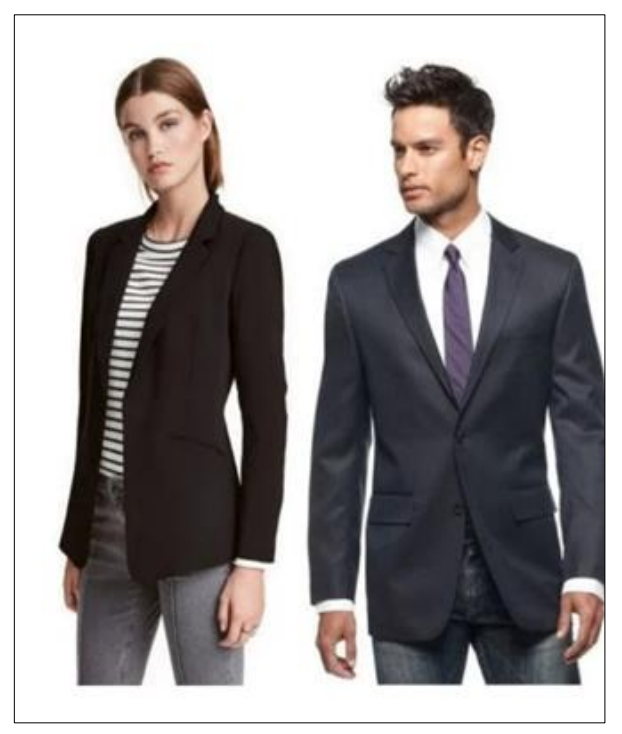

Figure 1 Best Blazers in black color for men \& women

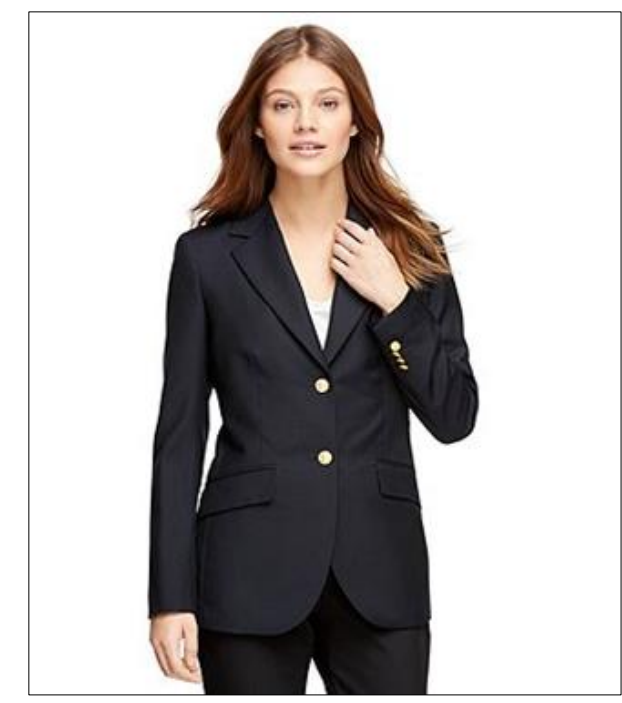

Figure 22 Button Single Breasted Black Blazers

\subsection{Button Single Breasted Black Blazers}

2 button single breasted black blazers is an American style blazer as shown in Fig. 2. It has a center vent. It mostly has notched labels with either a flapped pocket or patched pocket. It is a bit boxy in fit. It is more casual. It can be worn with denim without much hesitation [8]. 


\subsection{Button Single Breasted Black Blazers}

3 Button single-breasted Black Blazer for men has 3 buttons as shown in Fig. 3. It is known for its amazing fit. It is an English style blazer. It is preferred to be single-breasted and will make you look like a tree trunk. It emphasis on shoulders and chest [9]. It is easy to dress down with it

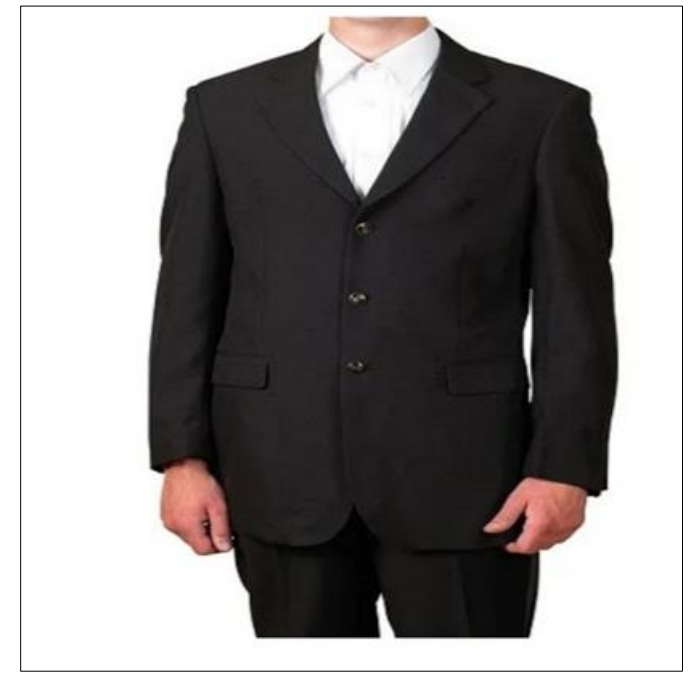

Figure 33 Button Single Breasted Black Blazers

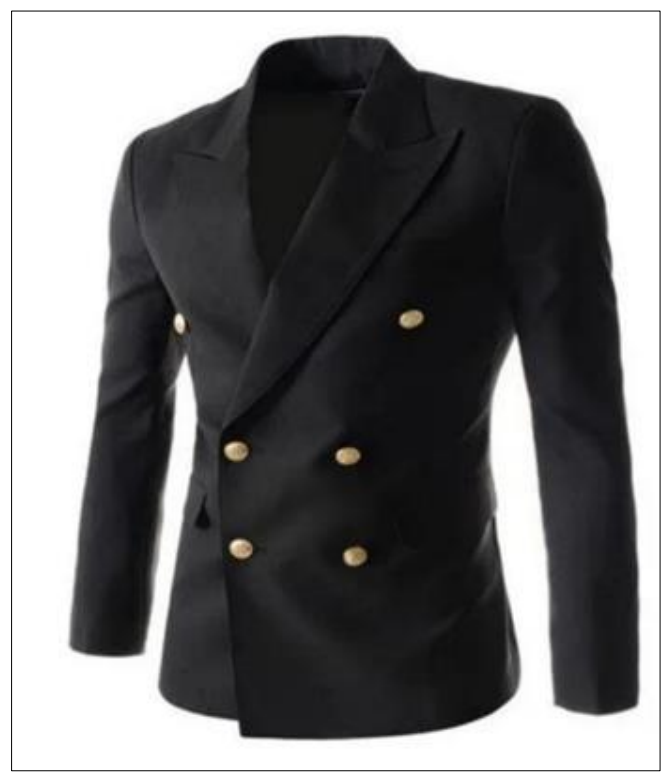

Figure 46 Button Double Breasted Black Blazers

\subsection{Button Double Breasted Black Blazers}

6 Button double-breasted black blazers have its origin from the British Royal Naval Army as shown in Fig. 4. It was made by the Navy Commander, H M S Blazer to impress Queen Victoria. He made it and fitted it with copper buttons. It is made double-breasted to give the right fit and protect from the chilly breeze [10].

\subsection{Men's Slim-Fit Black Blazers}

Slim fit black blazer for men is the modern-day fit. It is body-hugging. It is less boxy and straighter. It is mostly made up of linen. Women and men wear this style. It is a casual style. If you are taking a flight, or out for a Sunday brunch, then this is the right style for you. Many men wear it with ease. You can even team it with shorts [11]. 


\subsection{Wool Black Blazer for Men}

Wool is the most preferred choice in blazers as shown in Fig.5. It is soft and warm. You can weave it according to your needs. It serves the purpose to protect you from chilly weather. Mostly they come with self-print in the form of stripes. It is a traditional choice of material. If you want to go for both official and informal purposes and yet need to get protected from harsh winters, there is nothing better than this one. [12]

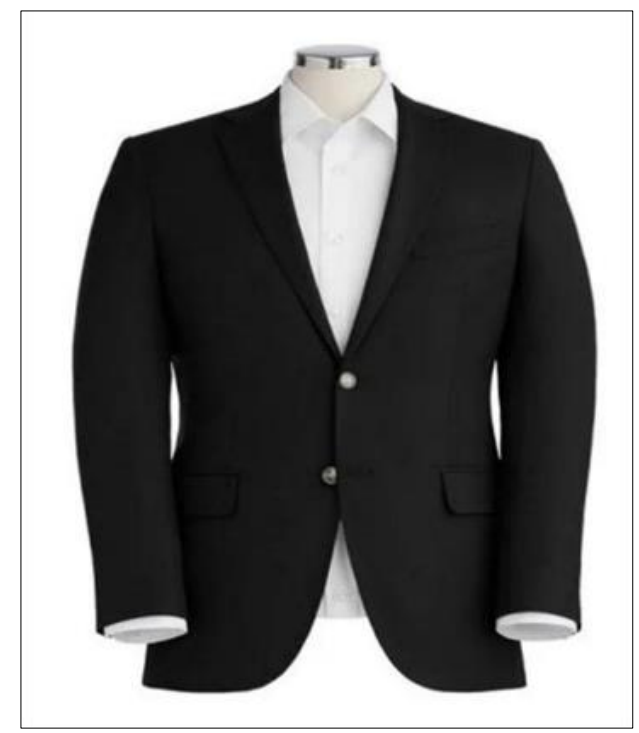

Figure 5 Wool Black Blazer for Men

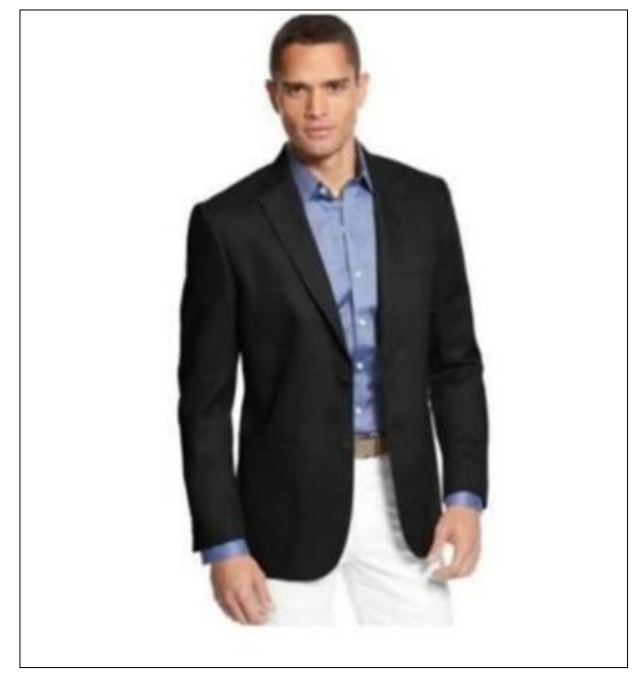

Figure 6 Linen black Blazers in Men’s Fashion

\subsection{Linen black Blazers in Men's Fashion}

In India, summers are very hot and humid. In this temperature, if you want to look stylish by sporting blazer then choose black linen blazer. Since it is made of linen, it is breathable and soft. It soaks sweat. It is also softer than woolen blazers. You can wear them to the beach or day outing without worrying about the temperature [13].

\subsection{Formal Black Blazers in Silk:}

Going to a big party or high-end dinner, then black silk blazer is your style. It is very rich to look at. It gives you a good fit because silk shapes up easily. Mostly the lining underneath is satin to give a shine. You can wear it with smart pants to give it a contrast look and tone down the shine [14]. 
Global Journal of Engineering and Technology Advances, 2021, 09(01), 011-035

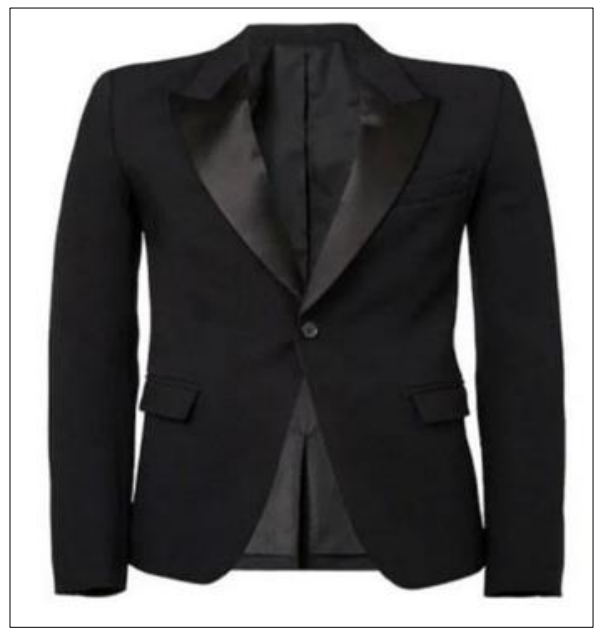

Figure 7 Formal Black Blazers in Silk

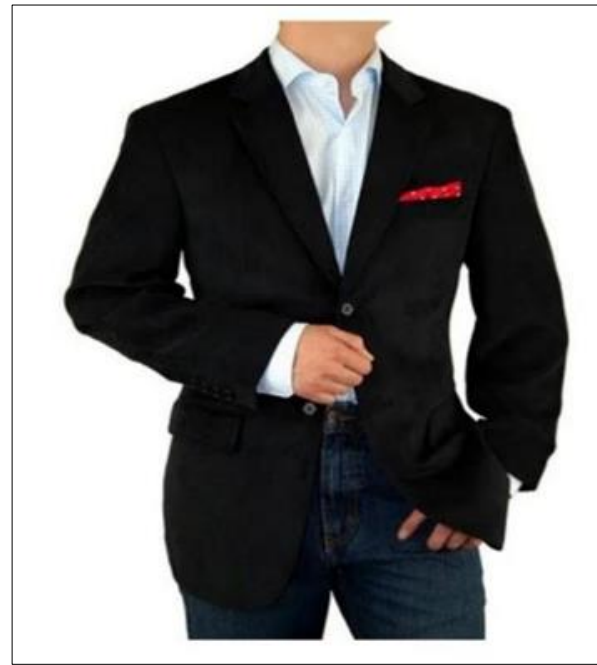

Figure 8 Traditional Corduroy Black Blazers

\section{Methodology}

\subsection{Flow Chart of Blazer Making}

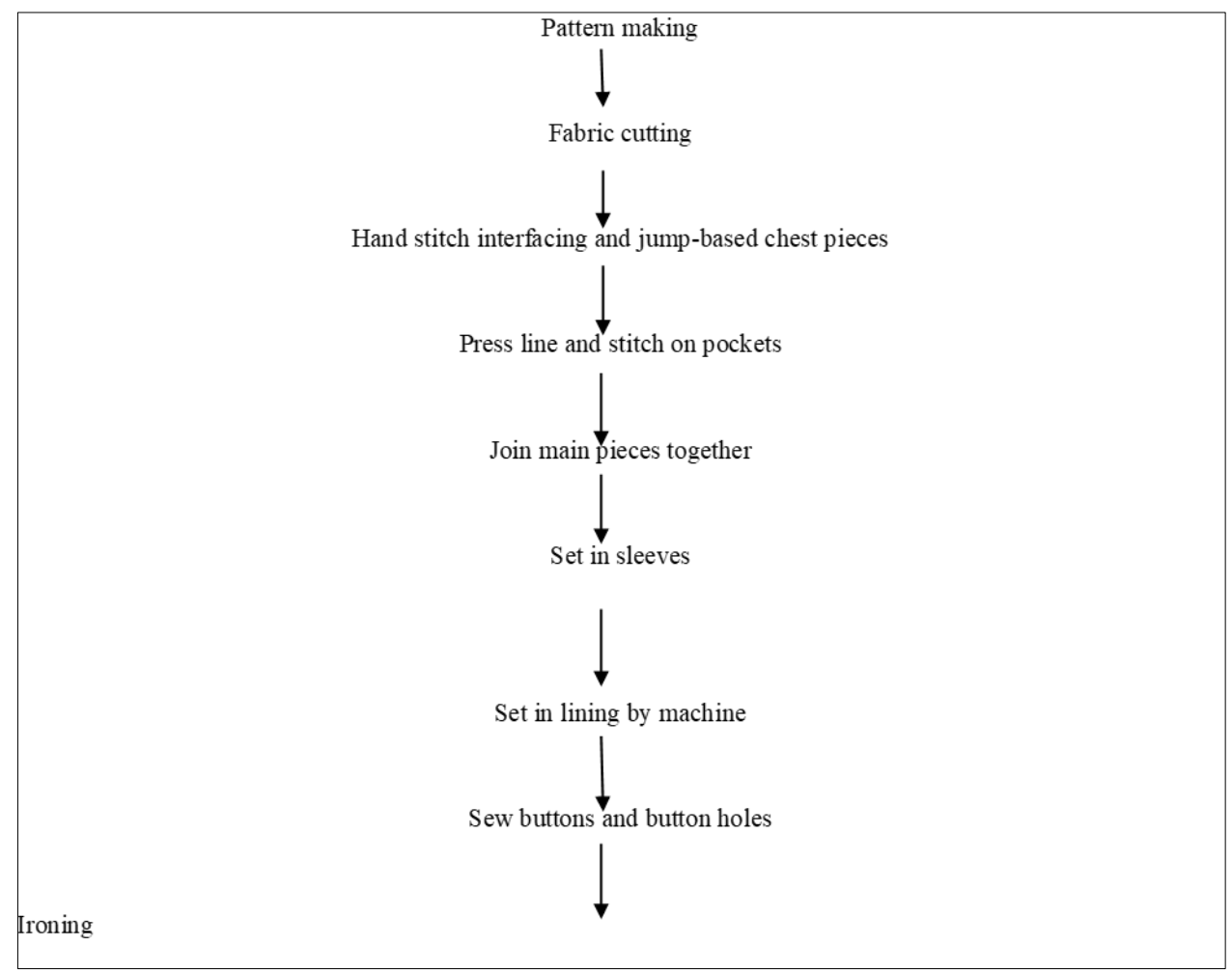

Figure 9 Flow Chart of Blazer Making

\subsection{Material of the Research}

\subsubsection{For pattern making:}

- Pattern Paper

- Pencil

- Scale

- Rubber 


\subsubsection{For Fabric Cutting}

- Tap

- Scissor

- Scale

- Marking Chalk

\subsubsection{For Blazer Making}

Table 1 Materials needed for Blazer making

\begin{tabular}{|l|c|}
\hline Name of the components & Quantity \\
\hline Twill Fabric & $2 \& 1 / 2$ yards \\
\hline Lining Fabric & 2 yards \\
\hline Interlining & 1 yard \\
\hline Fusing & $1 \& 1 / 2$ yards \\
\hline Shoulder Pad & 1 pair \\
\hline Felt & 1 piece \\
\hline Button & 8 pieces \\
\hline
\end{tabular}

\subsection{Procedure of the research}

\subsubsection{Measurement of the blazer}

A blazer jacket is one of those items that has to fit perfectly. One can get away with wearing a loose- fitting blouse or cardigan because the oversized look is quite trendy, but when it comes to blazer jackets, he or she needs to be fitted exactly to the body measurements [15].

\subsubsection{Size of blazer template}

Table 2 Different size measurement for Blazer

\begin{tabular}{|l|c|c|c|c|c|}
\hline Size & $\begin{array}{l}\text { Small } \\
\text { (In inch) }\end{array}$ & $\begin{array}{l}\text { Medium } \\
\text { (In inch) }\end{array}$ & $\begin{array}{l}\text { Large (In } \\
\text { inch) }\end{array}$ & $\begin{array}{l}\text { Extra-large } \\
\text { (In inch) }\end{array}$ & $\begin{array}{l}\text { Double } \\
\text { XL (In inch) }\end{array}$ \\
\hline Neck Size & 15 & 16 & 17 & 18 & 19 \\
\hline Body Length & 29 & 30 & 31 & 32 & 33 \\
\hline Chest Width & 40 & 42 & 44 & 46 & 48 \\
\hline Shoulder Width & 18.5 & 18.5 & 19 & 19.5 & 20 \\
\hline Waist Width & 36 & 38 & 40 & 42 & 44 \\
\hline Bottom width & 41 & 43 & 45 & 47 & 49 \\
\hline Sleeve Length & 24 & 24.5 & 25 & 25.5 & 26 \\
\hline Center back Length (CBL) & 28 & 29 & 30 & 31 & 32 \\
\hline Lapel width & 3 & 3 & 3 & 3 & 3 \\
\hline Sleeve opening & 5 & 5.5 & 5.5 & 6 & 6 \\
\hline Pocket dimension & $6 \times 2.25$ & $6 \times 2.25$ & $6 \times 2.25$ & $6 \times 2.25$ & $6 \times 2.25$ \\
\hline
\end{tabular}

Collar to shoulder: Place the measuring tape at the middle of the collar and pull down to the tip of the shoulder.

Shoulder to sleeve: Measure from the tip of the shoulder down to the bottom of the sleeve. 
Shoulder to shoulder: Place the measuring tape at the corner of one shoulder and pull across to the other shoulder. This is an important measurement as some people typically wear the same size but have different shoulder width.

Upper arm width: Place the measuring tape in the middle of the upper arm and measure from one side of the sleeve to the other. This measurement is important when it comes to bicep size.

Forearm width: Place the measuring tape in the middle of the forearm and measure from one side of the sleeve across to the other.

Chest width: Measure from the bottom of one armhole across the chest to the bottom of the opposite armhole.

Waist width: Place the measuring tape where the natural waist would fall, usually a bit lower than half way down the blazer, and measure from one side of the jacket across to the other.

Front length: Place the measuring tape in the middle of the collar and pull it down vertically to the bottom of the jacket.

Hip width: Measure from one of the bottom corners of the jacket across to the other.

Sleeve whole width: Measure the width of the sleeve by placing the measuring tape at one corner of the sleeve hold and pulling it across to the other side.

\subsection{Fabrication}

Fabric type of blazer: Synthetic twill fabric.

Ends per inch (EPI): 80

Picks per inch (PPI): 62

Warp Count: 40

Weft Count: 30

Fabric Width: 60

Fabric Specification:

Ends per inch $($ EPI) $\times$ Picks per inch $(\mathrm{PPI})$

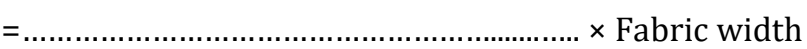

Warp count $\times$ Weft count

Or,

Warp count $\times$ Weft count

$\times$ Fabric width

Ends per inch (EPI) $\times$ Picks per inch (PPI)

Here,

Fabric specification:

$40 \times 30$ 


\subsection{Pattern making for blazer}

\subsubsection{Components of the blazer}

- Front part- 2

- $\quad$ Back part- 2

- $\quad$ Sleeve- 4

- $\quad$ Side panel- 2

- Welt pocket- 2

- $\quad$ Chest pocket- 1

- Lapel- 1

- Flap- 2

- Collar- 1

- Twill fabric- $2 \& 1 / 2$ yard

\subsubsection{Trimmings of blazer}

- Sewing thread

- $\quad$ Button -8 pieces

- Interlining- 1 yard

- $\quad$ Lining-2 yard

- Shoulder pad- 1 pair

- Fusing- $1 \& 1 / 2$ yard

- Felt- 1 piece

\subsection{Garment pattern}

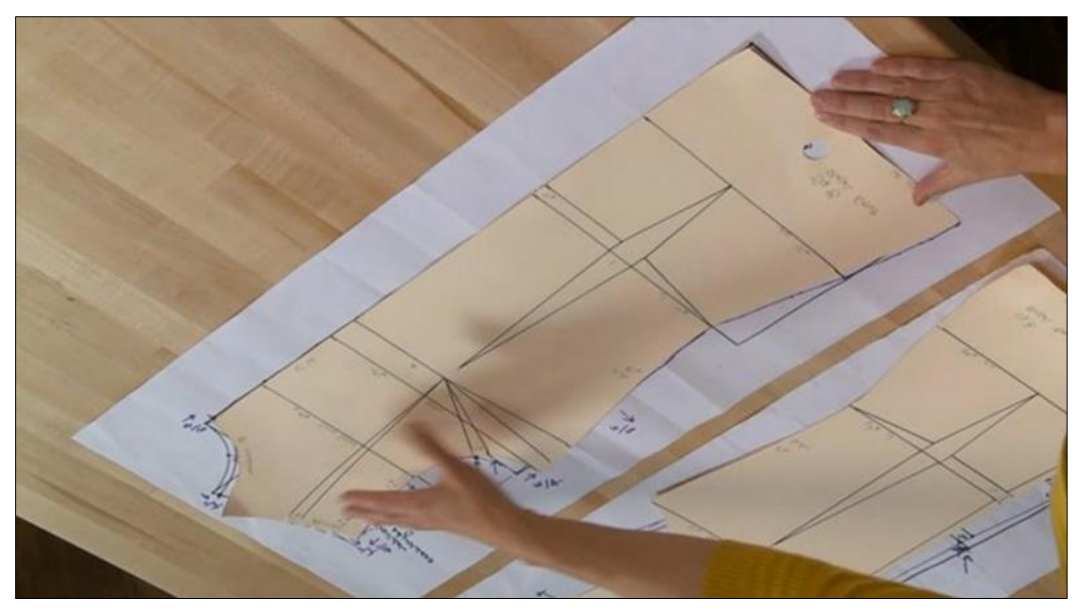

Figure 10 Garments pattern

Pattern is a hard paper which is made by following each individual component for a style of garment or apparel. Actually, pattern is a template from which the parts of a garment are traced onto fabric before being cut out and assembled. It is one of the most important parts of apparel industry. Pattern making is a highly skilled technique which calls for technical ability, sensitivity for design interpretation and a practical understanding of garment construction. Pattern making is a bridge function between design and production [16]. A basic or foundation pattern can be created by any of the two methods, namely, by drafting or by draping fabric on a model. Pattern drafting is defined as a technique or method of drawing patterns on brown paper with accuracy and precision, based on the body measurements or standard measurement chart. This is an efficient and economical method and can be manipulated to create the pattern for different styles by a technique known as flat pattern designing

\subsubsection{List of Pattern Making Tools}

There are various pattern making tools which are vastly used in apparel industry have pointed out in the below with their function [18]: 
- $\quad$ Straight pins,

- Straight pin holder,

- Scissors,

- Pencils and pens,

- Rulers,

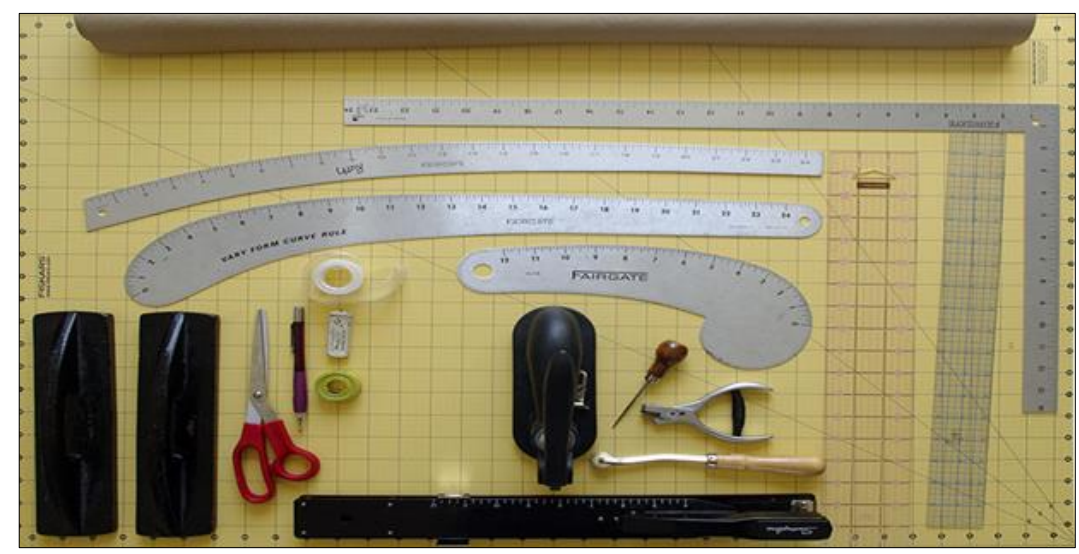

Figure 11 Pattern making Tools

- Curve rules,

- Hanger hooks or ringers,

- Push pins,

- Magic mend scotch tape,

- Black twill tape,

- Notched,

- Tracing wheels,

- Awl,

- Metal weight,

- Measuring tape,

- Tailors chalk.

\subsubsection{Pattern Making Process of Blazer}

Steps to prepare the pattern of blazer are given below [19]:

Here we will use only 4 Measurement,

So first we review the measurements,

Length $-76 \mathrm{~cm}$, Half Chest $-48 \mathrm{~cm}$, Sleeve Length $-64 \mathrm{~cm}$, Sleeve Opening $-14 \mathrm{~cm}$,

Half Chest - $48 \mathrm{~cm}$ (Remember It our main key)

Half chest- $48 \mathrm{~cm}$,

$1 / 2=24 \mathrm{~cm}$. one of the two

$1 / 3=16 \mathrm{~cm}$. one of the three

$1 / 4=12 \mathrm{~cm}$. one in one

$1 / 6=8 \mathrm{~cm}$. is one six 


\subsubsection{Formula calculates (half Chest)}

Starting blazer marking \& cutting part

- $\quad$ First we draw a line this is neck line

- back shoulder slop from CB seam - $4 \mathrm{~cm}$ down

- armhole depth half chest of half $1 / 2$ from shoulder line ( $5 \mathrm{~cm}$ above a mark for the back crotch point)

- Waist position from C.B neck seam - $48 \mathrm{~cm}$ down

- here is I will keep $76 \mathrm{~cm}$ for blazer Length

- here we deduct $2.5 \mathrm{~cm}$ at center back hip

- come to waist and here we deduct $2.5 \mathrm{~cm}$

- and come to chest point of armpit here we deduct $0.6 \mathrm{~cm}$

- come to center back seam here we deduct $0.5 \mathrm{~cm}$

- back neck width (chest- 1/6)

- here $2.5 \mathrm{~cm}$ up mark for back neck depth

- we mark for back neck seam line

- half shoulder (chest $1 / 4+10 \mathrm{~cm}$ add $1 \mathrm{~cm}$ )

- we make a vertical line to down from shoulder point

- we mark $1 \mathrm{~cm}$ out at hip

- we mark $1 \mathrm{~cm}$ in at waist

- we mark $1 \mathrm{~cm}$ out at back crotch point

- we start draw from hip connect Waist chest and back crotch point And back armhole line and we adding Seam margin $1 \mathrm{~cm}$ both side expect bottom

- start back cutting the back part Side part making We take back part before we cut and keep here for The making side and front part beads on backHere we mark similar as back for the make side and front

- make a vertical line for making side part

- $\quad$ side back width at hip chest $1 / 6+2 \mathrm{~cm}$ Mark a line for front side up to armpit

- side back width at waist chest $1 / 6+1 \mathrm{~cm}$

- $\quad$ side back width at armhole chest $1 / 6+1 \mathrm{~cm}$ We now drawing back side line connect to back crotch point -Front part-

- F- chest width at armhole (chest $1 / 2$ )

- F- waist width (chest $=1 / 2-3 \mathrm{~cm}$ )

- $\quad$ F- hip width (chest $=1 / 2$ )

- F- neck width from C.F (chest $1 / 4$ )

\subsection{Design pattern and collar}

Mark the position of the closing button $1 \mathrm{~cm}$ above the waist line and add $1.3 \mathrm{~cm}$ overlap. Draw a guideline for the front edge perpendicular to the hem line. Draw the curved cut-away front as shown in the illustration. The guideline for the front edge does not have to meet the center front at the hem. The angled construction is possible only if the abdomen width is up to $1 \mathrm{~cm}$ larger than the chest width.

Extend the shoulder seam $2 \mathrm{~cm}$ to the left for the lapel construction and mark the position of the lapel break. Measure the back neckline for the construction of the felt under collar.

Lengthen the lapel break line upward. Measure the determined back neckline minus $1 \mathrm{~cm}$ from the front neckline corner to the lapel break. From this point square out to the right and measure $1.2 \mathrm{~cm}$ for the collar roll and $2.5 \mathrm{~cm}$ for the collar stand. Draw the collar seam to the neckline. Draw the center back perpendicular to the collar seam line. Plot the shawl collar and the lapel according to the illustration. Measure and compare the collar seam and the neckline. The collar seam should be approximately $1 \mathrm{~cm}$ shorter than the neckline, since the collar gets longer when steam-pressed into shape.

Mark the welt pockets and the chest pocket according to the illustration. Mark the side vents. Draw a horizontal line from the pocket to the back-side seam and mark the length of the side vents $2 \mathrm{~cm}$ below this line. Draw the hip curves straight for the vent fold and extend the hem $0.8 \mathrm{~cm}$ at the vent fold. Draw the vent fold $4 \mathrm{~cm}$ wide. Draw the vent underlap $4 \mathrm{~cm}$ wide at the upper edge and $5 \mathrm{~cm}$ wide at the hem. Shorten the underlap to prevent showing at the hem. 


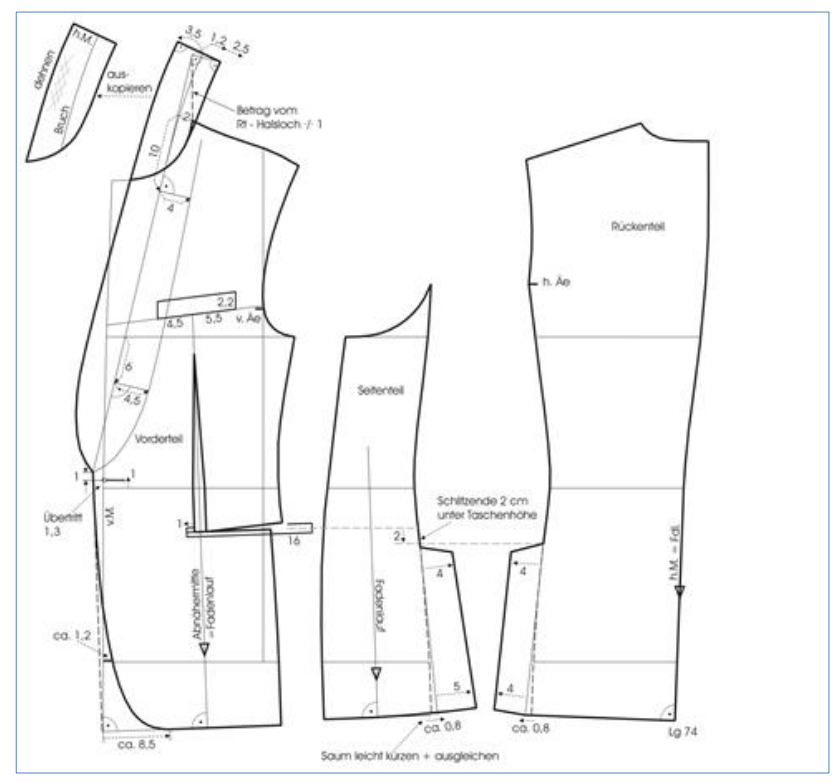

Figure 12 Collar \& pattern design

Mark the grain lines on the side panel and on the back-pattern perpendicular to the hemlines. On the front pattern, mark the grain line along the dart middle line.

\subsection{Sleeve}

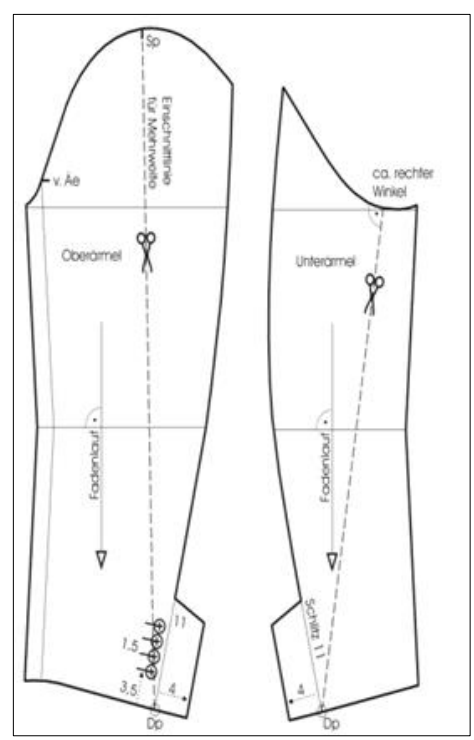

Figure 13 Sleeve

Determine the cap ease. The cap ease shoulder amount 5 to $8 \%$ for industrial manufacturing and 8 to $10 \%$ for a tailored jacket. Slash from the sleeve cap to the hemline and increase or decrease the ease by spreading or overlapping the sleeve pieces. Mark the sleeve vent $11 \mathrm{~cm}$ long for four buttonholes. Draft the overlap and under lap. Mark the button positions. Mark the grain line perpendicular to the elbow line.

\subsection{Cutting}

Cutting is one of the major process in garments manufacturing. Here garments parts are cutting according to the pattern. In garments cutting department, a process flow chart have to maintained to send the right measurement parts in the next process for making quality garments[20]. 
Global Journal of Engineering and Technology Advances, 2021, 09(01), 011-035

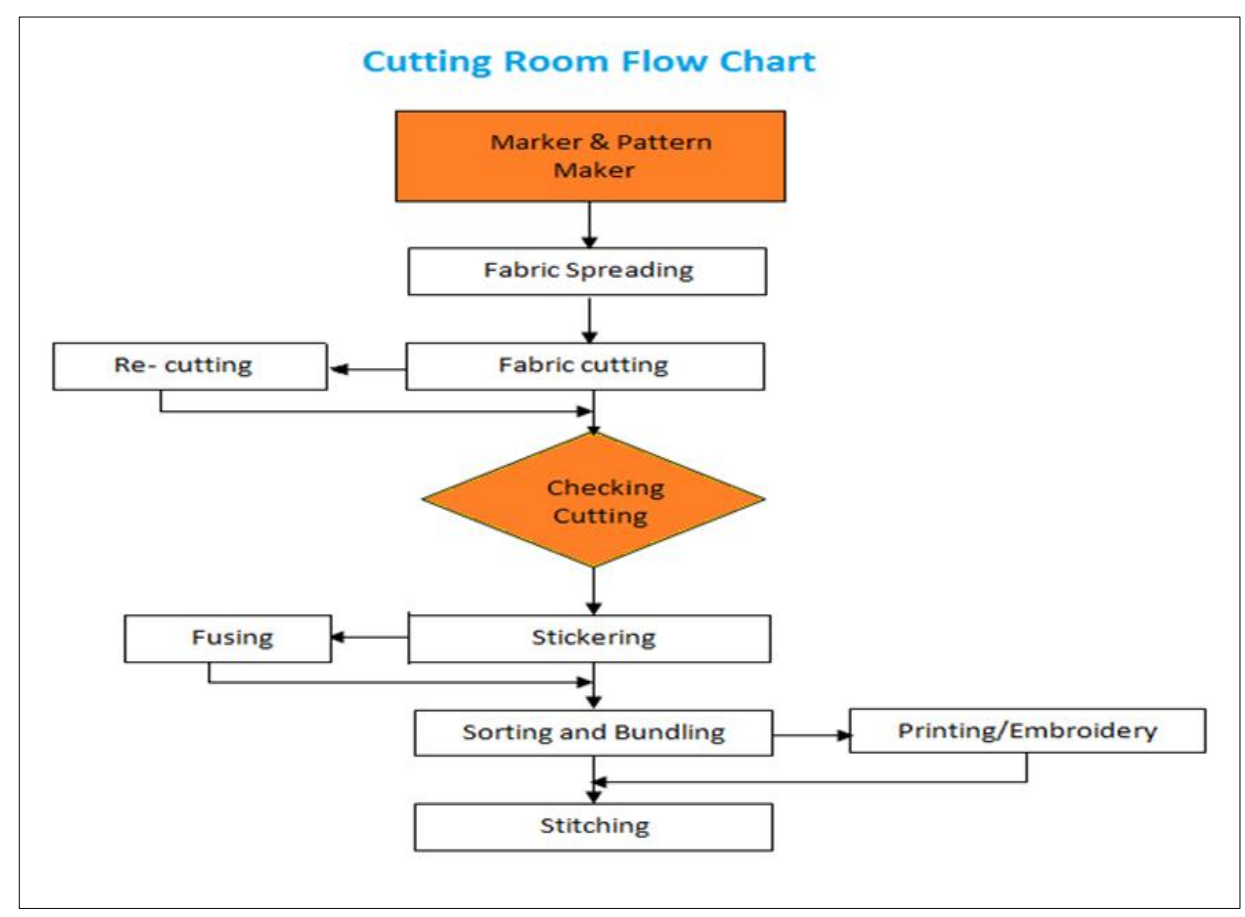

Figure 14 Cutting room flow chart

\subsubsection{Sewing sequence for blazer}

In garment industry; CAD system is used for cut the pattern. After passing the cutting section, different parts of the blazer are sent to the sewing section for assembling this. After sewing and final inspection by the quality control it is ready for sale in the market. 
3.9.2. Sewing sequence of the blazer is given below

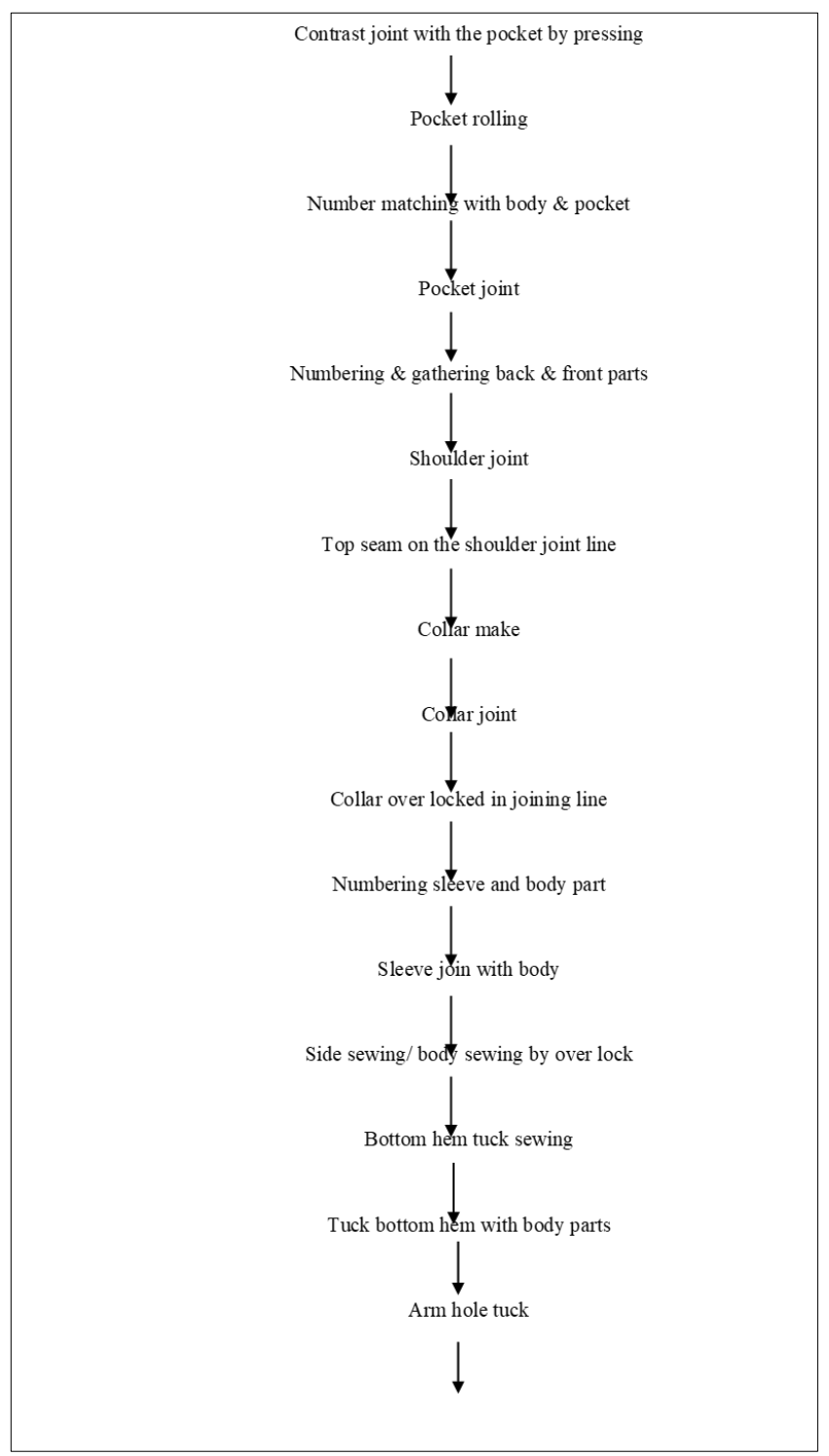

Figure 15 Sewing sequence of the blazer

\subsection{Operation breakdown}

Breakdown is a listing of the content of a job by elements [21][22]. A garment consists of some parts and some group of operations. Breakdown means to write down all parts and all process/ operation after one another lying with the complete garment according to process sequence.

\subsubsection{Operation breakdown of the blazer}

Table 3 Operation breakdown of the blazer

\begin{tabular}{|l|l|c|c|c|c|c|}
\hline SL No. & Front section operation & Machine type & $\begin{array}{l}\text { Basic time } \\
\text { (min) }\end{array}$ & $\begin{array}{l}\text { With } \\
\text { allowance }\end{array}$ & SAM (Min) & $\begin{array}{l}\text { SAM } \\
\text { sec }\end{array}$ \\
\hline 1 & Front and bottom edge making & S/N & 0.71 & 0.8378 & 0.67024 & 40.214 \\
\hline 2 & Dart making & S/N & 0.53 & 0.6254 & 0.50032 & 3.0192 \\
\hline 3 & Dart seam press & Iron & 0.56 & 0.6608 & 0.52864 & 30.019 \\
\hline 4 & Front side panel attach & D/N & 1.03 & 1.2154 & 0.97232 & 58.339 \\
\hline 5 & Centre back stitching & S/N & 0.6 & 0.708 & 0.97232 & 33.984 \\
\hline
\end{tabular}




\begin{tabular}{|l|l|c|c|c|c|c|}
\hline 6 & Armhole tape attach & S/N & 0.83 & 0.9794 & 0.5664 & 47.011 \\
\hline 7 & Side panel press & Helper & 1.7 & 2.006 & 0.78352 & 96.288 \\
\hline 8 & Breast pocket attach & S/N & 0.4 & 0.472 & 1.6084 & 22.656 \\
\hline 9 & Breast pocket press & D/N & 0.86 & 1.0148 & 0.3776 & 48.710 \\
\hline 10 & Welt pocket attach & S/N & 0.71 & 0.8378 & 0.81184 & 40.214 \\
\hline 11 & Welt pocket press & Helper & 0.65 & & 0.67024 & \\
\hline 12 & Welt pocket back tack & S/N & 1.00 & 1.18 & 0.944 & 56.64 \\
\hline 13 & Pocket bag close & S/N & 0.88 & 1.0384 & 0.83072 & 49.832 \\
\hline 14 & Canvas attach with press & Helper & 1.06 & 1.2508 & 1.00064 & 60.038 \\
\hline 15 & Canvas close & S/N & 0.75 & 0.885 & 0.708 & 42.48 \\
\hline 16 & Front body press & Helper & 0.96 & 1.1328 & 0.90624 & 54.341 \\
\hline 17 & Armhole canvas cutting & Cutting machine & 1.2 & 1.416 & 1.1326 & 67.968 \\
\hline 18 & Side seam & S/N & 0.91 & 1.0738 & 0.85904 & 51.542 \\
\hline 19 & Press side seam & S/N & 1.2 & 1.416 & 1.1328 & 67.968 \\
\hline 20 & Button press & Snap button & 0.73 & 0.8614 & 0.68912 & 41.347 \\
\hline 21 & Shoulder attach & S/N & 0.93 & 1.121 & 0.8964 & 53.808 \\
\hline 22 & Shoulder press & Iron & 0.96 & 0.96 & 1.1328 & 54.374 \\
\hline 23 & Shoulder pad attach & Helper & 0.71 & 0.71 & 0.8378 & 40.2144 \\
\hline Total & & & & & 20.3904 & 1223.424 \\
\hline
\end{tabular}

\begin{tabular}{|l|l|c|c|c|c|}
\hline SL No. & Lining section & $\begin{array}{l}\text { Basic time } \\
\text { (min) }\end{array}$ & $\begin{array}{l}\text { With } \\
\text { allowance }\end{array}$ & $\begin{array}{l}\text { SAM } \\
\text { (Min) }\end{array}$ & $\begin{array}{l}\text { SAM } \\
\text { sec }\end{array}$ \\
\hline 1 & Centre back attach & 0.86 & 1.0184 & 0.81184 & 48.7104 \\
\hline 2 & Side panel attach with back & 0.86 & 1.0184 & 0.81114 & 48.7104 \\
\hline 3 & Front facing attach with lining & 1.45 & 1.2334 & 1.8755 & 82.90 \\
\hline 4 & Press front facing/marking of pocket & 0.65 & 1.3425 & 0.90767 & 53.987 \\
\hline 5 & Saddle stitch & 0.35 & 1.777 & 0.57823 & 33.09 \\
\hline 6 & Lining welt pocket & 1.87 & 1.6753 & 0.37557 & 75.789 \\
\hline 7 & Press welt pocket & 1.36 & 1.8905 & 0.8653 & 50.547 \\
\hline 8 & Brand label attach with pocket bag & 1.78 & 1.9745 & 0.9754 & 43.096 \\
\hline 9 & Pocket bag attach and close & 0.97 & 1.8904 & 1.9786 & 56.098 \\
\hline 10 & Front side panel attach with back & 0.9 & 0.8964 & 0.765 & 58.0184 \\
\hline 11 & Shoulder attach & 1.2 & 1.9867 & 0.89 & 45.9876 \\
\hline 12 & Sweat shield & 1.67 & 0.5672 & 0.897 & 39.624 \\
\hline 13 & Sweat shield attach & 1.56 & 0.867 & 0.907 & 42.9868 \\
\hline 14 & Collar attach & 1.1 & 1.9784 & 0.4532 & 50.6743 \\
\hline 15 & Lining process & 1.3 & 1.9767 & 1.7864 & 47.8934 \\
\hline 16 & Neck board stitch & 1.76 & 1.9753 & 0.0854 & 48.0293 \\
\hline 17 & Collar press & 0.87 & 0.86743 & 0.786 & 23.948 \\
\hline 18 & Canvas attach/Blind hem & 0.52 & 0.6136 & 1.90754 & 29.202 \\
\hline Total & & & & & 879.2908 \\
\hline
\end{tabular}




\begin{tabular}{|c|c|c|c|c|c|}
\hline SL No. & Basic time ( Min) & With allowance & SAM (min) & & SAM in sec \\
\hline 1 & Sleeve head ready & 0.65 & 0.708 & 0.5664 & 33.984 \\
\hline 2 & Elbow seam lining stitch & 0.85 & 1.003 & 0.8024 & 48.144 \\
\hline 3 & Shell elbow seam press & 0.65 & 0.767 & 0.6136 & 38.186 \\
\hline 4 & Sleeve vent & 0.7 & 0.826 & 0.6608 & 39.648 \\
\hline 5 & Bottom press & 0.63 & 0.7434 & 0.59672 & 35.6832 \\
\hline 6 & Sleeve vent tack & 0.85 & 1.003 & 0.8024 & 48.144 \\
\hline 7 & Button marking & 0.88 & 1.0384 & 0.83072 & 49.8432 \\
\hline 8 & Button attach to sleeve & 0.35 & 0.8614 & 0.3304 & 41.3472 \\
\hline 9 & Sleeve head attach & 0.73 & 1.0974 & 0.83072 & 52.6752 \\
\hline 10 & Shell and lining attach & 0.93 & 1.416 & 0.68912 & 67.868 \\
\hline 11 & Inseam close (seam \& lining) & 1.2 & 0.888 & 0.87792 & 42.48 \\
\hline 12 & Inseam spelt press & 0.75 & 0.7788 & 1.1328 & 37.3824 \\
\hline 13 & Sleeve close & 0.66 & 0.5664 & 0.708 & 27.1872 \\
\hline 14 & Turn and press & 0.48 & 0.413 & 0.62304 & 67.988 \\
\hline Total & & & & 10.5162 & 630.9696 \\
\hline
\end{tabular}

\begin{tabular}{|c|c|c|c|c|c|c|}
\hline SL No. & Assembly operation 1 & Machine type & $\begin{array}{l}\text { Basic } \\
\text { time(min) }\end{array}$ & $\begin{array}{l}\text { With } \\
\text { allowance }\end{array}$ & $\begin{array}{l}\text { SAM } \\
\text { (Min) }\end{array}$ & $\begin{array}{l}\text { SAM in } \\
\text { sec }\end{array}$ \\
\hline 1 & Matching of parts & Helper & 0.9 & 1.062 & 0.48961 & 50.976 \\
\hline 2 & Lapel peak & $\mathrm{S} / \mathrm{N}$ & 1.4 & 1.652 & 0.7552 & 79.0785 \\
\hline 3 & Collar zigzag & $\mathrm{D} / \mathrm{N}$ & 0.6 & 0.944 & 1.2744 & 45.9732 \\
\hline 4 & Front edge stitch & $\mathrm{S} / \mathrm{N}$ & 1.35 & 1.593 & 0.8496 & 76.07656 \\
\hline 5 & $\begin{array}{l}\text { Sticker removing and manual } \\
\text { cutting }\end{array}$ & Helper & 0.9 & 1.063 & 0.84072 & 50.923 \\
\hline 6 & Front edge press open & $\mathrm{S} / \mathrm{N}$ & 0.88 & 1.0384 & 2.6 & 49.678 \\
\hline 7 & Button closing stitch & $\mathrm{D} / \mathrm{N}$ & 2.5 & 3.2 & 0.826 & 153.856 \\
\hline 8 & Piping pressing & Helper & 3 & 3.54 & 1.888 & 169.529 \\
\hline 9 & Lapel pressing & $\mathrm{S} / \mathrm{N}$ & 2 & 2.36 & 0.6608 & 133.584 \\
\hline 10 & Button hole marking & Helper & 0.7 & 0.826 & 0.708 & 39.560 \\
\hline 11 & Button hole flower hole & Eyelet machine & 0.75 & 0.885 & 0.5192 & 42.8956 \\
\hline 12 & Hanger loop+Bartack & $\mathrm{D} / \mathrm{N}$ & 0.55 & 0.649 & 15.0491 & 31.152 \\
\hline Total & & & & & 15.05 & 902.94 \\
\hline
\end{tabular}

\begin{tabular}{|l|l|l|c|c|c|c|}
\hline SL no & Assembly operation 2 & $\begin{array}{l}\text { Machine } \\
\text { type }\end{array}$ & Basic time & With allowance & $\begin{array}{l}\text { SAM in } \\
\text { min }\end{array}$ & SAM in sec \\
\hline 1 & Sleeve attach & S/N & 2.16 & 2.5488 & 2.03904 & 122.3424 \\
\hline 2 & Sleeve crown pad pressing & Helper & 0.95 & 1.121 & 0.8968 & 53.808 \\
\hline
\end{tabular}




\begin{tabular}{|l|l|l|c|c|c|c|}
\hline 3 & Shoulder pad pressing & Helper & 0.8 & 1.06 & 0.849 & 50.94 \\
\hline 4 & Armhole basting & D/N & 1.15 & 1.357 & 1.0865 & 65.136 \\
\hline 5 & Lining close & S/N & 3.16 & 3.7288 & 2.98304 & 178.9824 \\
\hline 6 & Vent top stitch & S/N & 1 & 1.18 & 0.944 & 56.64 \\
\hline 7 & Sleeve lock & S/N & & & & \\
\hline 8 & Thread trimming & S/N & & & 0.5664 & 33.984 \\
\hline & Total value= & & 0.6 & 0.708 & 9.36388 & 561.8328 \\
\hline
\end{tabular}

\begin{tabular}{|l|c|c|}
\hline \multicolumn{3}{|c|}{ Section wise SAM } \\
\hline Section & SAS (standard sec) & SAM (standard min) \\
\hline Lining & 879.05 & 14.65 \\
\hline Sleeve & 630.96 & 10.52 \\
\hline Front & 1223.42 & 20.39 \\
\hline Assembly 1 & 902.94 & 15.05 \\
\hline Assembly 2 & 561.83 & 9.36 \\
\hline Collar \& small parts & 523.83 & 5.40 \\
\hline
\end{tabular}

\section{Results and discussion}

\subsection{Seam Slippage Test}

\subsubsection{Seam Slippage}

Seam slippage is a fabric problem especially for fabrics that contain slippery yarns or that have an open structure or where the number of warp and weft interlacing is low. Such factors mean that one set of yarns may be easily pulled through the other. Seam slippage is the condition where a seam sewn in the fabric opens under load. Some of this gap may close on removal of the load but some of it may be a permanent deformation. This test method is used to determine the resistance to slippage of filling yarns over warp yarns, or warp yarns over filling yarns, using a standard seam.

\subsubsection{Procedure of Seam Slippage Test}

The British Standard test for seam slippage is a test of the second type. Five warp and five weft specimens each $100 \mathrm{~mm}$ $\mathrm{X} 350 \mathrm{~mm}$ are used. Each sample is folded $100 \mathrm{~mm}$ from one end and a seam is sewed $20 \mathrm{~mm}$ from the fold line using the special sewing thread and sewing machine settings which are detailed in the standard. The layout of the sample is shown in Fig. After sewing the folded part of the fabric is cut away $12 \mathrm{~mm}$ from the fold line leaving the seam $8 \mathrm{~mm}$ from the cut edge. A standard strength tester equipped with $25 \mathrm{~mm}$ grab test jaws is used, the gauge length being set to $75 \mathrm{~mm}$.

Just before the test the sample is cut into two parts one with the seam and one without but with each part containing the same set of warp or weft threads. The sample without a seam is first stretched in the tensile tester up to a load of $200 \mathrm{~N}$ and a force elongation curve drawn. The matching sample with the seam is then tested in the same way making sure that the force elongation curve starts from the same zero position. In order to find the force required to open the seam a given distance, the separation of the curves at a force of $5 \mathrm{~N}$ is measured and this distance is added to the seam opening specified (usually $6 \mathrm{~mm}$ but some specifications require $5 \mathrm{~mm}$ ) making appropriate allowance for the horizontal scale of the chart. Next the point on the curves where there is a separation of this distance is located and the value of load at this point is read off the chart. 


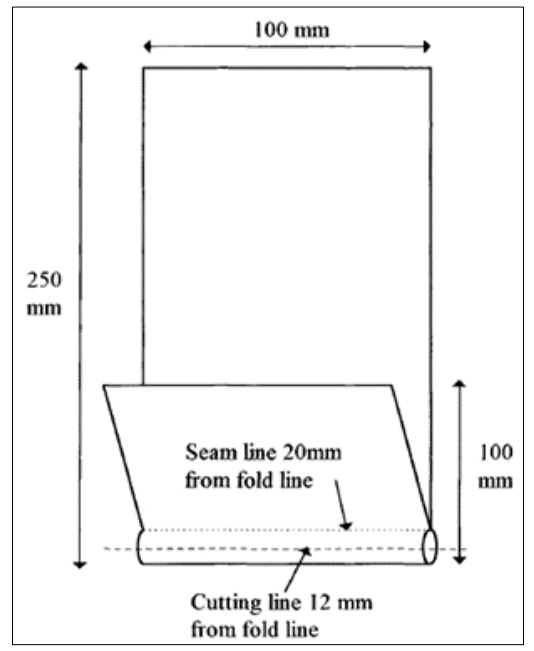

Figure 16 Slippage test

\subsubsection{Result}

If the curves do not reach the specified separation below $200 \mathrm{~N}$ then the result is recorded as 'more than $200 \mathrm{~N}$ '.

\subsubsection{Discussion}

Warp setting parameters do not have a sufficient influence on the slippage resistance of yarns at a seam in woven fabrics. The weave of fabric and weft setting parameters have a substantial influence on the slippage resistance of yarns at a seam in woven fabrics.

\subsection{Seam Strength Testing}

\subsubsection{Procedure of the testing}

To determine the seam strength of the sewn seams under transverse loading condition, an Instron Tensile Testing machine of CRE type is used. The full load of the cell range $100 \mathrm{~kg}$ is used with $8 \mathrm{~cm}$ per min traversing speed, the distance between jaws is $6 \mathrm{~cm}$, the size of the jaws are $5 \mathrm{~cm} * 4 \mathrm{~cm}$. The method of the fixing test specimen in the jaws are shown in the following fig.15

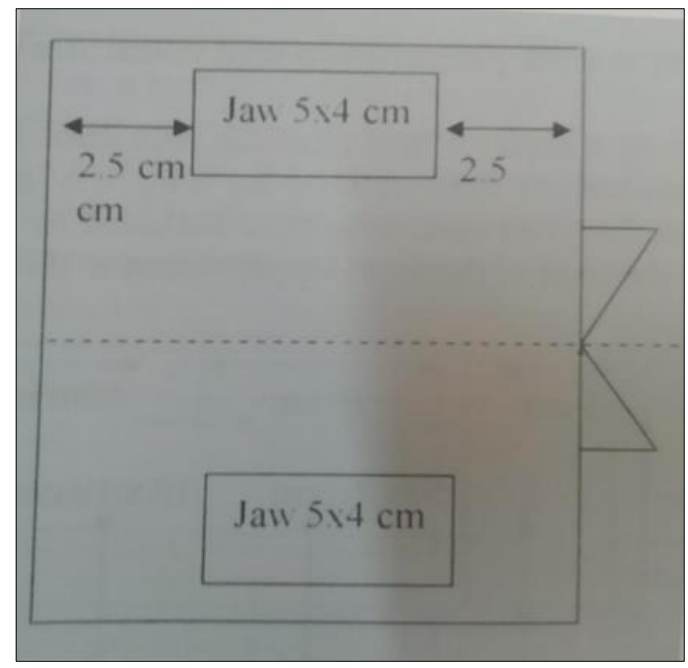

Figure 17 Seam strength test

\subsubsection{Result}

The breaking strength and breaking behavior of each specimen is observed and recorded which is shown in the table 
Table 4 Seam Strength Testing

\begin{tabular}{|c|c|l|c|l|}
\hline No. of stitches/cm & \multicolumn{2}{|c|}{ Warp way length } & \multicolumn{2}{c|}{ Weft way length } \\
\hline & Strength kg & Mode of failure & Strength kg & Mode of failure \\
\hline 2.3 & 25.5 & seam slippage & 19.5 & Seam breakage but not slippage \\
\hline 3.5 & 31.5 & Do & 28 & \\
\hline 4.7 & 35.75 & Do & 35 & \\
\hline 5.9 & 34.5 & Do & 43.6 & \\
\hline 7.1 & 34.0 & Do & 54 & \\
\hline
\end{tabular}

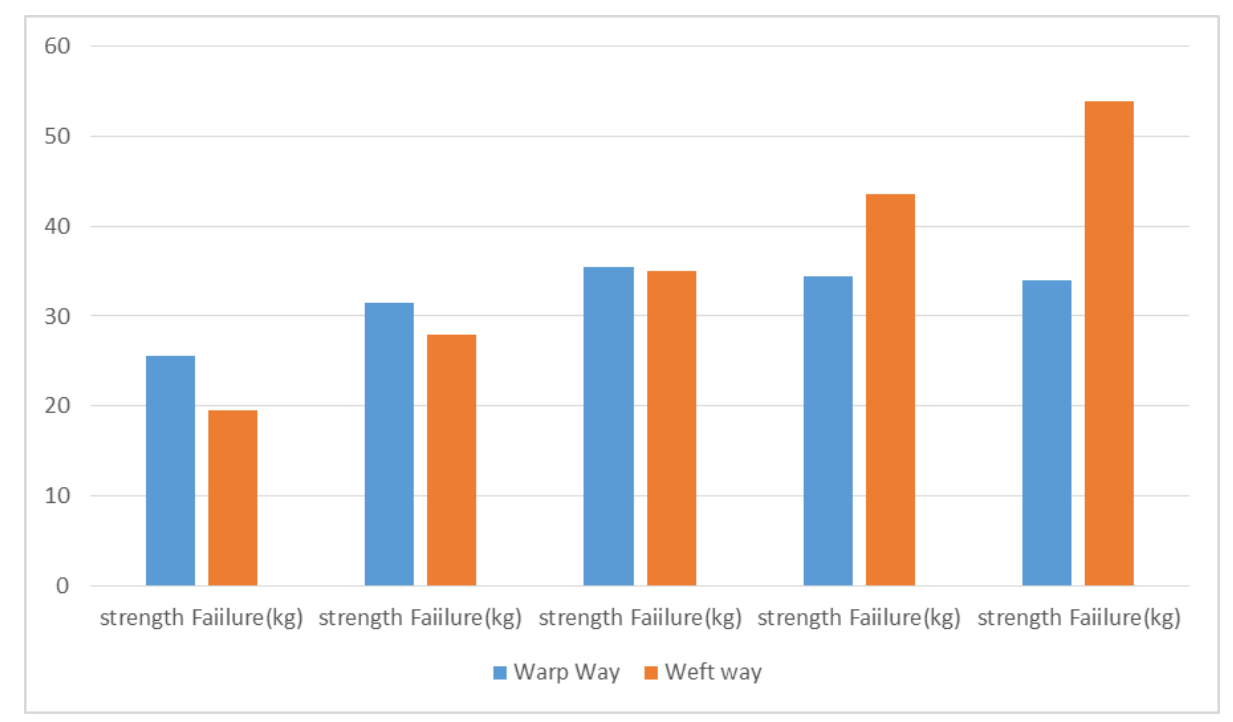

Figure 18 Seam strength Test

\subsubsection{Discussion}

From the result it was shown that different stitching threads will show different result on seam strength. Types of fabric and their structural properties have significant effect on seam strength. Higher seam strength of thread is prone for giving higher seam strength shows better functional performance of seam. Seam strength increases with the increase in sewing thread linear density.

\subsection{Tensile strength}

Tensile strength of the fabric means the strength along the warp-wise or weft-wise direction of the fabric. The textile fibers are anisotropic in nature, as the yarn is made of fibers and fabric is made of yarn, so the anisotropic behavior of fibers is clearly visible in the fabric. The tensile strength of fabric plays an important role in the quality of end product to be produced from it. Good tensile strength relates to the good life of fabric. So the tensile strength of fabric is checked after each chemical process and especially after the weaving process before any chemical treatment.

\subsubsection{Observations \& Calculations}

Table 5 Weft-wise fabric strength

\begin{tabular}{|l|l|l|l|l|l|l|}
\hline Sr. \# & $\mathbf{1}$ & $\mathbf{2}$ & $\mathbf{3}$ & $\mathbf{4}$ & $\mathbf{5}$ & Mean value \\
\hline Tensile strengtj (Kg) & 82 & 88 & 80 & 76 & 78 & 81 \\
\hline
\end{tabular}


Table 6 Warp-wise fabric strenght

\begin{tabular}{|c|c|}
\hline Sr.\# & Tensile Strength (Kg) \\
\hline 1 & 112 \\
\hline 2 & 110 \\
\hline 3 & 120 \\
\hline 4 & 113 \\
\hline 5 & 114 \\
\hline Mean Values & 114 \\
\hline
\end{tabular}

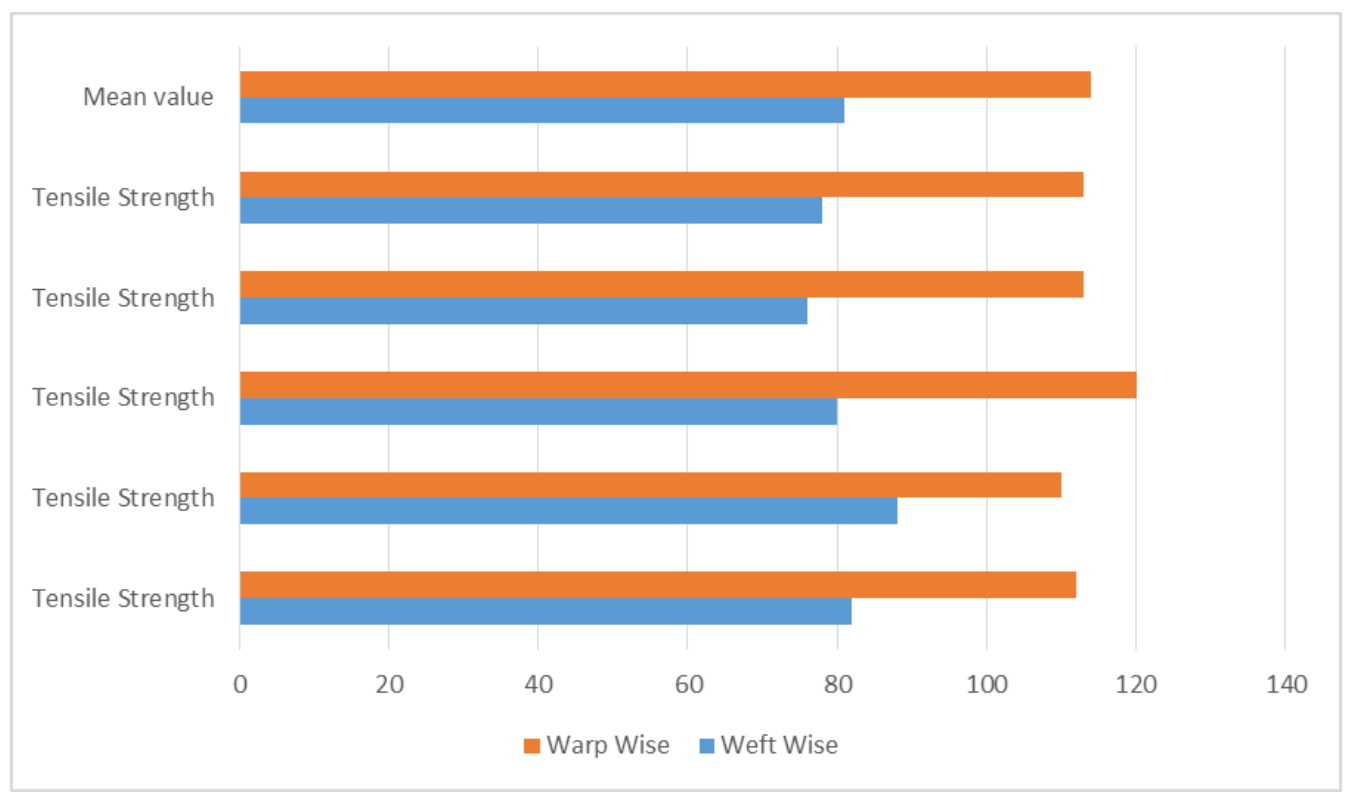

Figure 19 Tensile strength

\subsubsection{Sample preparation}

5 samples for warp direction

5 samples for weft direction

First taken a sample of $(60 \mathrm{~mm} \times 300 \mathrm{~mm})$ and then frayed down to $(50 \mathrm{~mm} \times 300 \mathrm{~mm})$

Test procedure:

Sample is clamped in the jaws

CRE $500 \mathrm{~mm}$ per minute loading

Gauge length $200 \mathrm{~mm}$

\subsubsection{Test result}

Mean breaking force

Mean elongation at break 


\subsubsection{Grab test (US Style)}

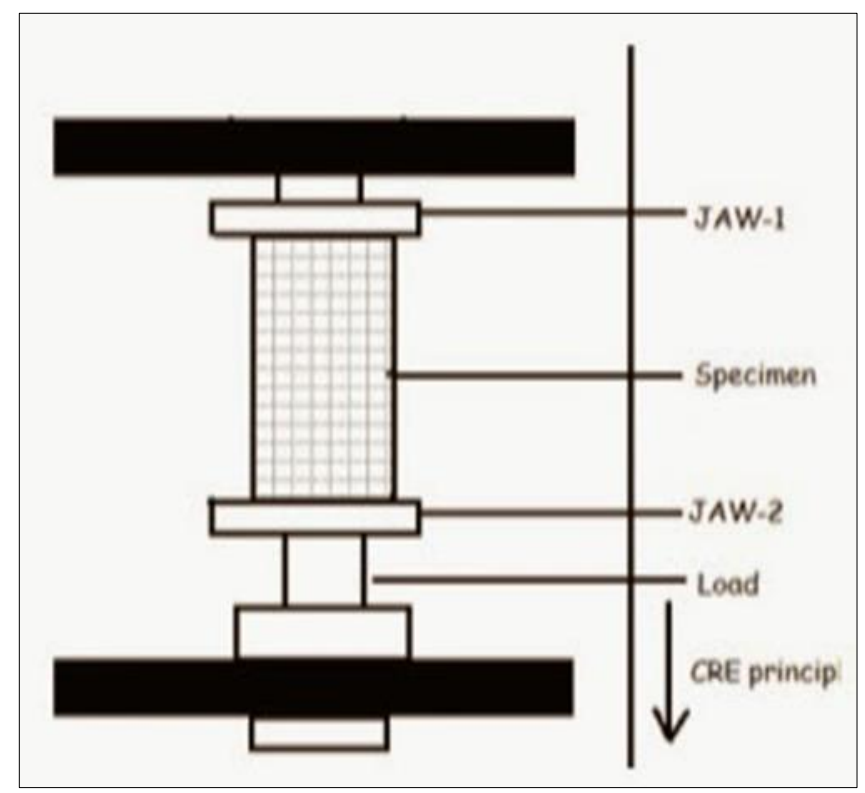

Figure 20 Grab test

Sampling preparation:

Sample size: $100 \times 1500 \mathrm{~mm}$

Jaw width: $25 \mathrm{~mm}$

Gauge length: $75 \mathrm{~mm}$

Test procedure:

Sample is clamped between the jaw

Speed is adjusted so then sample is broken in $20 \pm 3$ seconds

\subsubsection{Test results}

Mean breaking force.

Mean elongation at break

Tensile Strength

Weft-wise tensile strength $=81 \mathrm{Kg}$

Warp-wise tensile strength $=114 \mathrm{Kg}$

The results show that the warp-wise tensile strength of the fabric is more than that of the weft-wise tensile strength of the fabric. There are many factors responsible for this:

- $\quad$ The warp yarn has size material on it applied during the weaving preparation process, while weft yarn has no size material.

- The ends/inch of the fabric is more than that of picks/inch of the fabric.

\subsection{Color fastness to rubbing}

Color fastness to rubbing is the resistance ti fading of dyed Textiles when rubbed against a rough surface. 


\subsubsection{Sample preparation}

A $10 \mathrm{~cm} \times 4 \mathrm{~cm}$ dyed sample to be test is cut out. There are two types of adjacent fabrics, single fiber fabric and multiple fiber fabric. In the case of multi fibre fabric only one specimen, 6 types of fibers side by side, is required and in the case of single fibre fabric two adjacent fabrics are required.

Another two pieces of fabric sample which are scoured, bleached and undyed sample of $5 \mathrm{~cm} \times 4 \mathrm{~cm}$ sample also taken.

Now the tested sample is placed between two places of undyed fabric measuring, $5 \mathrm{~cm} \times 4 \mathrm{~cm}$ and there pieces are held together by stitching round the edges leaving $5 \mathrm{~cm} \times 4 \mathrm{~cm}$ exposed.

The composition of one of the colour less materials enclosing the specimen will be the same as the dyed sample and the other will be as indicated.

4.4.2. Result

\begin{tabular}{|l|c|c|c|}
\hline Serial no. & \multicolumn{2}{|l|}{ Description } & Result \\
\hline 01. & \multicolumn{2}{|c|}{ IS0105×12:1993 } & \\
\hline Staining & Lengthwise & Width wise & Average grade \\
\hline Dry & 3 & 3 & 3 \\
\hline Wet & $2-3$ & $2-3$ & $2-3$ \\
\hline
\end{tabular}

\subsubsection{Interpretation of grade}

- Very poor

- Poor

- Fair

- Good

- Excellent

\subsection{Color fastness to wash test}

The resistance to the loss of color of any dyed or printed material to washing is referred to as its wash fastness. If dye molecules have not penetrated inside the inter polymer chain space of fiber or have not attached to the fire with strong attractive force, poor wash fastness result.

\subsubsection{Working procedure}

Cut a specimen into $10 \mathrm{~cm} * 4 \mathrm{~cm}$ from bulk and make sure all colors are included in it.

Sewing the specimen with multi fiber fabric with same size along all four edges.

Making the solution of $5 \mathrm{gm}$ per $200 \mathrm{ml}$ distilled water. HDC, bleaching and others chemicals may be used.

Putting the solution, steel ball, specimen with multi fiber fabric onto the container. Steel ball dia is $0.6 \mathrm{~cm}$ and 30 balls are used.

Set the container with above materials into washing machine.

Switch on the washing machine and rinse the temperature during washing at $100^{\circ} \mathrm{C}$ and fixed it till 30 minutes.

After that remove specimen at the end of the wash and rinse twice for 1 minute in two separate $100 \mathrm{ml}$ of water at $40^{\circ} \mathrm{C}$.

Then squeezing with cold water of the sample is done by hand wash.

Then drying is done at a temperature in the air not exceeding $60^{\circ} \mathrm{c}$.

After that stitching is broken out from all edges which done with multi fibber fabric. 
At last measuring the staining and color change by grey scale and make a test report.

4.5.2. Result

\begin{tabular}{|l|l|l|}
\hline Serial no. & Description of test & Result \\
\hline 01. & Color fastness to washing method follow: ISO 105C06:1994 & Good \\
\hline & & Grade \\
\hline & Color change in shade & 4 \\
\hline & Staining in acetate & 4 \\
\hline & Cotton & 4 \\
\hline & Polyamide & 4 \\
\hline & Polyester & 4 \\
\hline & Acrylic & 4 \\
\hline & Wool & 4 \\
\hline
\end{tabular}

\subsection{Button Pull Test}

Actually "Button Pull Test" is used to determine the pulling strength of any type of snaps used in garments for producing goods. Mainly it used to determine the holding or breaking strength of prong-ring attached snap fasteners onto garments to ensure button fixed on the product properly.

Consist of an upper snap clamp, a lower fabric \& force gauge mounted on a stand. The pull test is the mandatory for any type of garments product use button.

\subsubsection{Procedure for Button Pull Test}

Mainly for pull test you will always need to follow the buyer requirement for pulling strength. If a buyer does not give any requirement. So, you can follow own your company's procedure.

The standard procedure is continued pulling 15 (Second) in 93.4 /no. weight for all attaching component kike button, rivet, eyelet, snap etc.

If any item they fail, then that should be removed from production \& speared as a reject.

"Pull test should be done five pieces from each style 2 time every day \& keep record \& documents for everyday"

\subsubsection{Pull Testing Requirement}

Table 7 Pull Testing Requirement

\begin{tabular}{|l|l|l|l|l|}
\hline Name of button & Weight(newton) & Weight(kg) & Weight (L.B.S) & Time(second) \\
\hline Placket button & 93.4 & 9.52 & 212 & 10 \\
\hline Down button & 93.4 & 9.52 & 212 & 10 \\
\hline
\end{tabular}




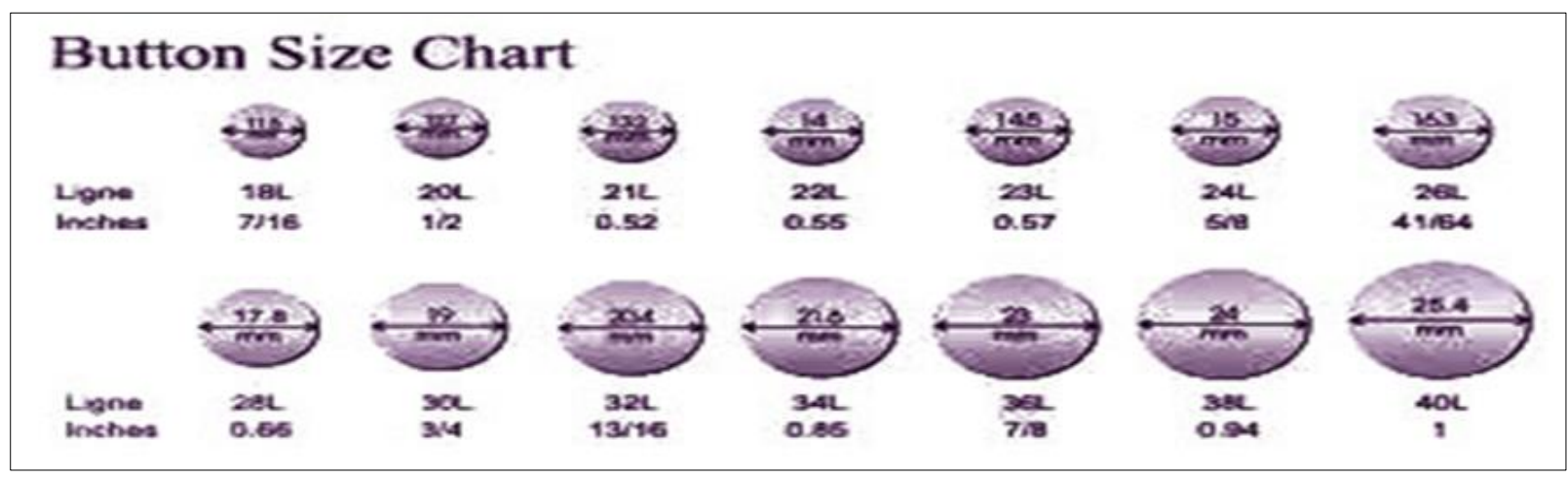

Figure 21 Types of button

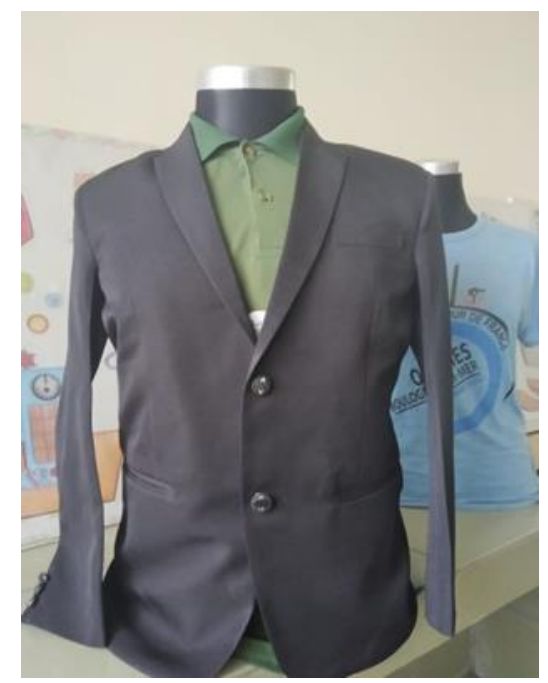

Figure 22 Balzer (Made by "F" Group)

\section{Conclusion}

Blazer is the world's most demanding and costly clothing. This aristocratic costume is an interest for both men and women. That is why the research mostly focuses on making blazers exportable in vast amounts in the world involved in the maker of clothes. This would increase our export value and enhance our economic status. Our goal is to provide the basic details on blazer industry with line balancing, job studies, time analysis and blazer production process. We based on the necessity of machinery, textiles, and clothing and blazer accessories during our project. We have even tried to measure around SMV for blazer production. By different tests including seam strength, seam slippage test and tensile strength test of the garments, we have determined the consistency of the fabric.

We attempted to gather original knowledge to complete the report during the entire study period. We didn't receive all details because of some restriction, but we think that future research will come very soon on this topic

\section{Compliance with ethical standards}

\section{Acknowledgments}

We will to acknowledge the efforts of my employer for given the opportunity to carry out the research work in the Textile Engineering College, Noakhali, Bangladesh. 


\section{Disclosure of conflict of interest}

None.

\section{References}

[1] Industrial and Mining Water Research Unit - Wikipedia [Internet]. En.wikipedia.org. 2021 [cited 12 October 2021]. Available from: https://en.wikipedia.org/wiki/Industrial_and_Mining_Water_Research_Unit

[2] Zeleny M. The Innovation Factory: On the Relationship between Management Systems, Knowledge Management and Production of Innovations. Innovations 2005, Zilina 2005.

[3] [Internet]. 2021 [cited 12 October 2021]. Available from: https://www.bls.gov/ooh/architecture-andengineering/industrial-engineers.htm

[4] Industrial engineering work study in garments? - Answers [Internet]. Answers. 2021 [cited 12 October 2021]. Available from: https://www.answers.com/Q/Industrial_engineering_work_study_in_garments

[5] How to Calculate Efficiency of a Production Line? [Internet]. Online Clothing Study. 2021 [cited 12 October 2021]. Available from: https://www.onlineclothingstudy.com/2011/09/4-how-to-calculate-efficiency-of.html

[6] Understanding Textiles for a Merchandiser by Prof. Dr. Engr. Shah Alimuzzaman Belal, CTex, and FTI, UK.

[7] Mogahzy, Y E. Engineering Textiles: Integrating the Design and Manufacture of Textile Products (First ed.). Woodhead Publishing. 2009; P. 362: ISBN 978-1-84569-048-9.

[8] [Internet]. 2021 [cited $12 \quad$ October 2021]. Available https://www.researchgate.net/publication/354329305_Man_Made_Textiles_in_India

[9] [Internet]. Scribd.com. $2021 \quad$ [cited 12 October 2021]. Available from: https://www.scribd.com/presentation/307207154/CO2-Molding-Process 